\title{
P-Cu alloy as anode materials for lithium ion batteries: a first- principles study
}

\author{
Zhaowen Huang ${ }^{1, *}$, Benjing Chen ${ }^{1}$, Jingyang $\mathrm{Li}^{1}$ and Lingzhi Zhao ${ }^{2}$ \\ ${ }^{1}$ College of energy and automotive engineering, Shunde Polytechnic, Foshan 528300, China \\ ${ }^{2}$ Laboratory of Nanophotonic Functional Materials and Devices, South China Normal University, Guangzhou 510631, China
}

\begin{abstract}
In this paper, based on the first principle method, the mechanism of lithium intercalation and deintercalation of P-Cu alloy as anode material of lithium-ion battery was studied. The results followed that the volume expansion coefficient of Li-P-Cu is small, $59.4650 \%$ for $\mathrm{Li} 2 \mathrm{PCu} 3$ and $61.4071 \%$ for $\mathrm{Li}_{2} \mathrm{P}_{2} \mathrm{Cu}$, indicating that the introduction of $\mathrm{Cu}$ can effectively inhibit the volume expansion of phosphorus. And $\mathrm{PCu}_{3}$ is superior to $\mathrm{P}_{2} \mathrm{Cu}$ in terms of volume expansion coefficient and lithium intercalation formation energy and good conductivity.
\end{abstract}

\section{Introduction}

Lithium ion battery has become an indispensable energy storage system[1-2]. However, the capacity of commercial anode materials is close to its theoretical limit $(372 \mathrm{mAh} / \mathrm{g})[3-4]$, so it is difficult to make a big breakthrough in recent years.

Phosphorus based anode materials are popular because of their theoretical specific capacity of 2596 $\mathrm{mAh} / \mathrm{g}[5-6]$. However, due to the volume effect in the charging and discharging process[7], low conductivity and the hidden danger from high activity, they have not been commercialized. The formation of "P-M" binary system by adding the second component is regarded as an effective solution, such as P-Fe system[8], P-Cu system[9] and P-Ni system[10]. However, due to the lack of mechanism, the research progress is slow.

In this paper, the mechanism of intercalation and delithiation of P-Cu alloy as anode material of lithiumion battery is deeply studied by first-principles method. The key parameters such as volume expansion coefficient, lithium intercalation formation energy and theoretical specific capacity are comprehensively analysed to find out the capacity loss mechanism and provide theoretical basis for experimental research.

\section{Computation and Structure}

\subsection{Computation Method}

All the molecular simulations in this paper are carried out by CASTEP module. The Schrodinger equation of single electron can be obtained by using functional variation to calculate the best form of single electron state.

$$
\begin{gathered}
{\left[-\frac{\nabla^{2}}{2 \mathrm{~m}}+V_{\mathrm{ext}}(\vec{r})+V_{\mathrm{xc}}(\vec{r})+V_{\mathrm{eff}}(\vec{r}, r(\vec{r}))\right] \varphi_{n}(\vec{r})=\varepsilon_{i} \varphi_{n}(\overrightarrow{\mathrm{r}})} \\
\rho(\vec{r})=\sum_{n} a_{n}\left|\varphi_{n}(\vec{r})\right|^{2}
\end{gathered}
$$

Here ${ }^{-\frac{\nabla^{2}}{2 \mathrm{~m}}}$ is the effective kinetic energy, $V_{\text {ext }}(\vec{r})$ is the field potential, $V_{\mathrm{xc}}(\vec{r})$ is the the exchange correlation potential, $V_{\text {eff }}(\vec{r}, \rho(\vec{r}))$ is the effective potential, $\rho(\vec{r})$ is the electronic density of states, ${ }^{a_{n}}$ is the number of internal electronic states.

Combined with the basic properties of materials, the generalized gradient approximation (GGA) and the modified density functional theory of PW91 are used in the calculation. The electron exchange correlation energy can be defined as a function of charge density and gradient.

$$
E_{\mathrm{xc}}^{\mathrm{GGA}}[\rho]=\int f_{\mathrm{xc}}[\rho(\vec{r}),|\nabla \rho(\vec{r})|] d r
$$

And the BFGS method is used to optimize the geometry of the cells. In the self-consistent calculation, the cut band can be taken as $10 \mathrm{eV}$, and the k-point is taken as $1^{*} 1 * 1$ grid point based on the Monkhorst-Pack method.

\subsection{Structure Model}

According to ICSD 2009, only $\mathrm{PCu}_{3}$ and $\mathrm{P}_{2} \mathrm{Cu}$ are stable alloy phases. The space type of $\mathrm{PCu}_{3}$ is $\mathrm{P}-3 \mathrm{Cl}$, space group number is 165 , and it is an orthorhombic hexahedral structure. $\mathrm{Cu}$ atoms occupy the positions of $2 \mathrm{~b}, 4 \mathrm{~d}$ and $12 \mathrm{~g}$, and the atomic coordinates are $(0,0,0)$, $(0.3333,0.6667,0.17)$ and $(0.69,0.07,0.08)$. $\mathrm{P}$ atoms

\footnotetext{
* Corresponding author: outstandingmore@163.com
} 
occupy the position of $6 \mathrm{f}$, and the coordinates are $(\mathrm{x}=$ $0.38, \mathrm{y}=0, \mathrm{z}=0.25)$.

The phase space group type of $\mathrm{P}_{2} \mathrm{Cu}$ alloy belongs to P21/C1, space group No.14, monoclinic system, PDF standard card No.18-452, all the atoms are located in $4 \mathrm{e}$ position, $\mathrm{Cu}$ atoms occupy the vertex position (0.14344, $0.46071,0.41602)$, the coordinates of $\mathrm{P}$ occupied position are $(0.24958,0.7789,0.6997)$ and $(0.40648$, $0.1139,0.797)$, respectively, According to the spatial symmetry distribution, the lattice constants $\mathrm{a}=0.58004 \mathrm{~nm}, \mathrm{~b}=0.48063 \mathrm{~nm}, \mathrm{c}=0.75263 \mathrm{~nm}$. The lattice structure model is shown in Fig.1(a)(c), and the lattice structure diagram after lithium intercalation is shown in Fig.1(b)(d).

Table 1. The structure parameter and atoms' sites of $\mathrm{P}-\mathrm{Cu}$ alloy interphases.

\begin{tabular}{|c|c|c|c|c|c|}
\hline \multirow[b]{2}{*}{ Phase } & \multirow[b]{2}{*}{ Space } & \multirow[b]{2}{*}{ Atom } & \multicolumn{3}{|c|}{ Site } \\
\hline & & & $x$ & $y$ & $z$ \\
\hline \multirow{4}{*}{$\mathrm{PCu}_{3}$} & \multirow{4}{*}{$\mathrm{P}-3 \mathrm{C} 1$} & $\mathrm{Cu}$ & 0 & 0 & 0 \\
\hline & & $\mathrm{Cu}$ & 0.3333 & 0.6667 & 0.17 \\
\hline & & $\mathrm{Cu}$ & 0.69 & 0.07 & 0.08 \\
\hline & & $\mathrm{P}$ & 0.38 & 0 & 0.25 \\
\hline \multirow{3}{*}{$\mathrm{P}_{2} \mathrm{Cu}$} & \multirow{3}{*}{$\mathrm{P} 21 / \mathrm{C} 1$} & $\mathrm{Cu}$ & 0.14344 & 0.46071 & 0.41602 \\
\hline & & $\mathrm{P}$ & 0.24958 & 0.7789 & 0.6997 \\
\hline & & $\mathrm{P}$ & 0.40648 & 0.1139 & 0.58025 \\
\hline
\end{tabular}

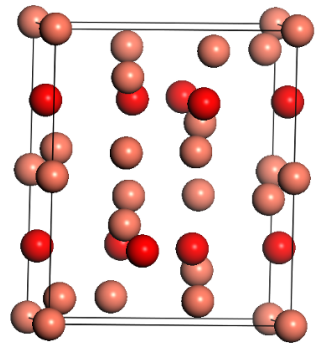

(a) $\mathrm{PCu}_{3}$

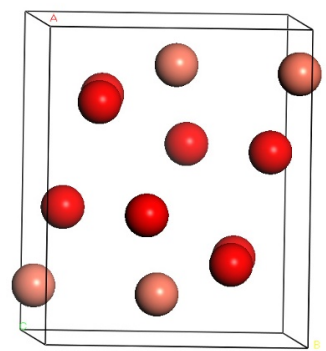

(c) $\mathrm{P}_{2} \mathrm{Cu}$

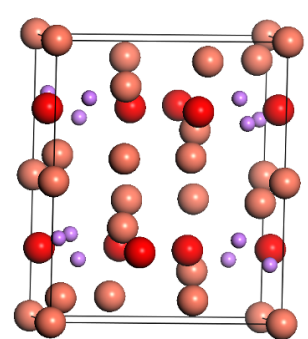

(b) $\mathrm{Li}_{2} \mathrm{PCu}_{3}$

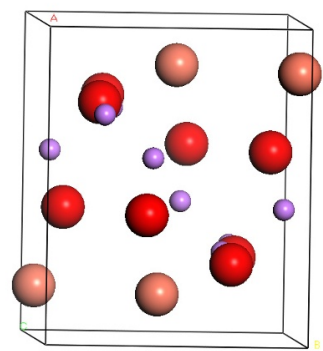

(d) $\mathrm{Li}_{2} \mathrm{P}_{2} \mathrm{Cu}$
Fig. 1. Structure model of the P-Cu alloy interphases before and after lithium intercalation.

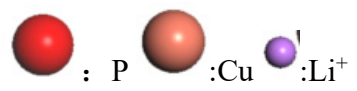

The lithium intercalation reaction of $\mathrm{P}-\mathrm{Cu}$ alloy is defined by equation (4), and the lithium intercalation formation energy is calculated by equation (5). The volume expansion coefficient is calculated by equation (6). V is the volume after lithium intercalation, and V0 is the volume before lithium intercalation. Equation (7) is used to calculate the theoretical lithium intercalation capacity, where Fis the Faraday constant and $\mathrm{M}$ is the relative molecular weight material of negative ions. The lithium intercalation potential can be calculated by equation (8).

$$
\mathrm{P}_{y} \mathrm{Fe}_{z}+x \mathrm{Li}^{+}=\mathrm{Li}_{x} \mathrm{P}_{y} \mathrm{Fe}_{z}
$$

$$
\begin{gathered}
\mathrm{E}=-\frac{1}{x}\left[\mathrm{E}_{\text {total }}\left(\mathrm{Li}_{x} \mathrm{P}_{y} \mathrm{Fe}_{z}\right)-\mathrm{E}_{\text {total }}\left(\mathrm{P}_{y} \mathrm{Fe}_{z}\right)-x \mathrm{E}\left(\mathrm{Li}_{\text {ion }}\right)\right] \\
\eta=\frac{\mathrm{V}-\mathrm{V}_{0}}{\mathrm{~V}_{0}} \times 100 \% \\
\mathrm{C}=\frac{x \cdot \mathrm{F}}{\varepsilon \cdot \mathrm{M}} \\
U \approx-\Delta E / \Delta x
\end{gathered}
$$

\section{Computation Result and Analysis}

For Li-P-Cu alloy, the volume expansion coefficient is small. For $\mathrm{Li}_{2} \mathrm{PCu}_{3}$, the volume expansion coefficient is only $59.4650 \%$. For $\mathrm{Li}_{2} \mathrm{P}_{2} \mathrm{Cu}$, the volume expansion coefficient is $61.4071 \%$, which is slightly higher than that of graphite anode material. The theoretical specific capacity of P-rich phase $\mathrm{P}_{2} \mathrm{Cu}$ is $427.1153 \mathrm{mAh} / \mathrm{g}$. However, the lithium intercalation formation energy of $\mathrm{Li}_{2} \mathrm{PCu}_{3}$ is $2.36 \mathrm{eV}$, and that of $\mathrm{Li}_{2} \mathrm{P}_{2} \mathrm{Cu}$ is even as high as $2.9853 \mathrm{eV}$. According to the "dead lithium phase" theory, the high bond energy leads to the lithium ion can not be separated again in the subsequent discharge process, resulting in the loss of active lithium ion. Although P-rich phase $\mathrm{P}_{2} \mathrm{Cu}$ has higher theoretical specific capacity, $\mathrm{PCu}_{3}$ is superior to $\mathrm{P}_{2} \mathrm{Cu}$ in terms of volume expansion coefficient and lithium intercalation formation energy. 
Table 2. Total energy, formation energy, cell volume, relative expansion ratio, specific capacity and lithium intercalation potential for $\mathrm{P}-\mathrm{Cu}$ alloy interphases

\begin{tabular}{|c|c|c|c|c|c|c|}
\hline Samples & $\begin{array}{c}\text { Total energy } \\
(\mathrm{eV})\end{array}$ & $\begin{array}{c}\text { Formation } \\
\text { energy(eV) }\end{array}$ & $\begin{array}{c}\text { cell } \\
\text { volume/ } \times 10^{-3} \\
\mathrm{~nm}^{3}\end{array}$ & $\begin{array}{c}\text { Expansion ratio } \\
(\%)\end{array}$ & $\begin{array}{c}\text { Capacity } \\
(\mathrm{mAh} / \mathrm{g})\end{array}$ & $\begin{array}{c}\text { Lithium } \\
\text { intercalation } \\
\text { potential/V }\end{array}$ \\
\hline $\mathrm{PCu}_{3}$ & -4614.4750 & --- & 50.2983 & --- & --- \\
\hline $\mathrm{Li}_{2} \mathrm{PCu}_{3}$ & -4995.2458 & 2.36 & 80.2082 & 59.4650 & 241.9998 & 2.36 \\
\hline $\mathrm{P}_{2} \mathrm{Cu}$ & -1838.4128 & --- & 48.1755 & --- & --- & -- \\
\hline $\mathrm{Li}_{2} \mathrm{P}_{2} \mathrm{Cu}$ & -2220.4288 & 2.9853 & 77.7587 & 61.4071 & 427.1153 & 2.9853 \\
\hline
\end{tabular}

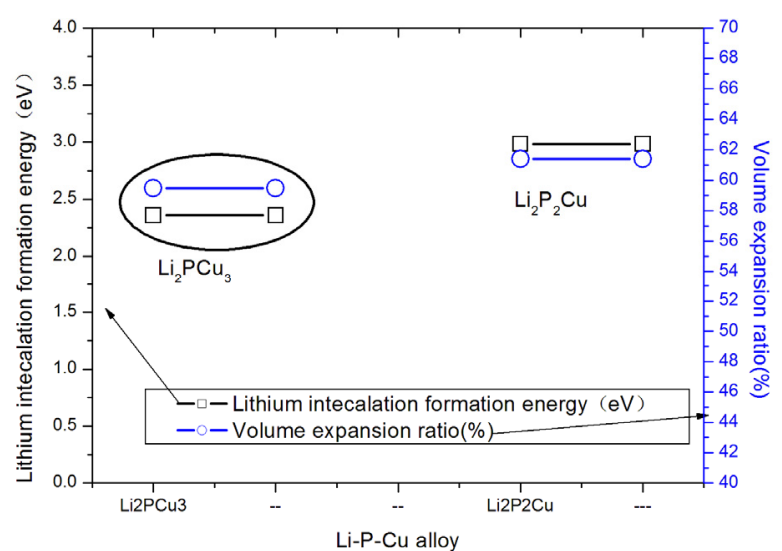

Fig. 2. Volume expansion ratio, Li intercalation potential of $\mathrm{P}$ $\mathrm{Cu}$ alloy interphases.

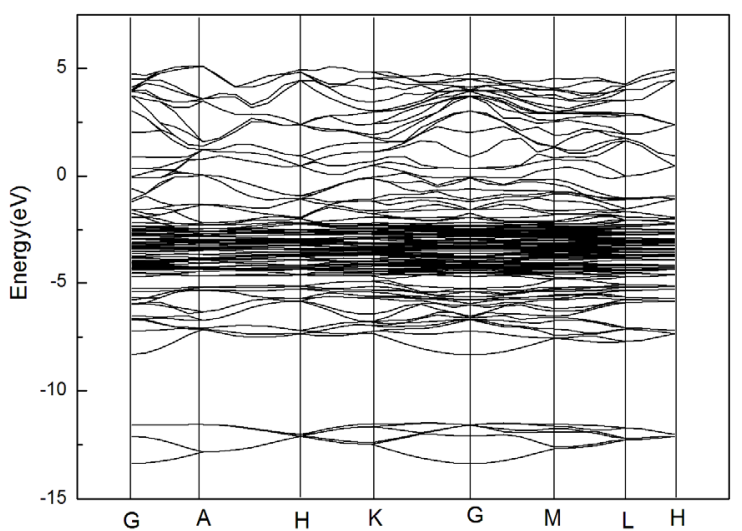

(a) $\mathrm{PCu}_{3}$ band structure

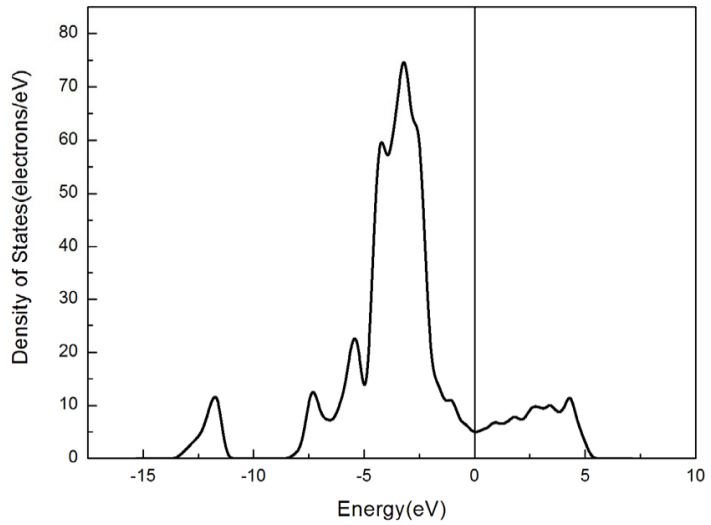

(b) $\mathrm{PCu}_{3} \mathrm{TDOS}$

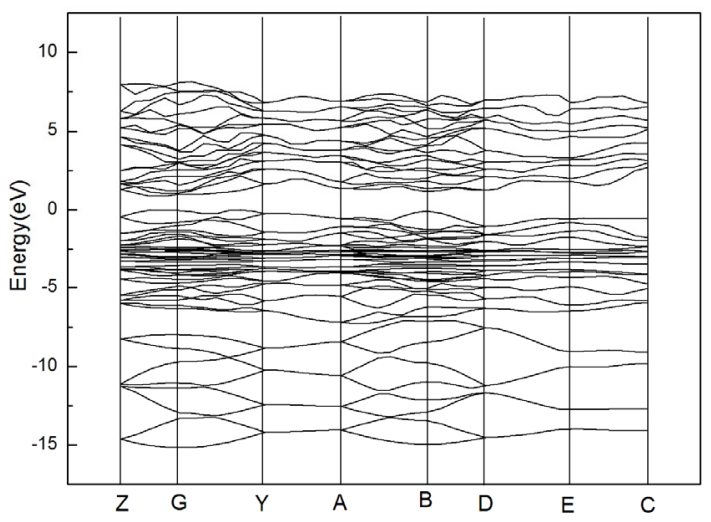

(c) $\mathrm{P}_{2} \mathrm{Cu}$ band structure 


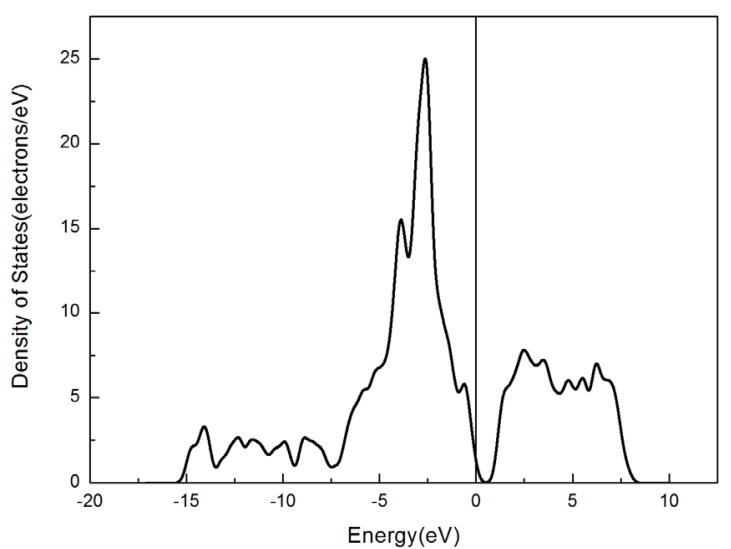

(d) $\mathrm{P}_{2} \mathrm{Cu}$ TDOS

Fig. 3. Band structure and total density of states for $\mathrm{P}-\mathrm{Cu}$ alloy interphases.

In the band structure, the cross of the valence band and conduction band near the Fermi level represents the conductivity of the material. In the total density of states diagram, the density of states near the Fermi level also reflects the conductivity of the material. For the anode material of lithium-ion battery, the conductivity directly affects the transport characteristics of lithium ion in the material, directly affects whether the material has high rate of high current charge and discharge performance, and affects the impedance of the whole battery.

The band structures and density of states of the $\mathrm{P}-\mathrm{Cu}$ alloy phases are showed in Fig.3. Fig. 3 (a) shows the band structure of $\mathrm{PCu}_{3}$. The results show that there is a dense cross between conduction band and valence band near Fermi level, which shows the characteristics of conductor, indicating that $\mathrm{PCu}_{3}$ has good conductivity. Fig. 3 (c) shows the band structure of $\mathrm{P}_{2} \mathrm{Cu}$. The results show that there is also a cross between conduction band and valence band near Fermi level, which shows the characteristics of conductor. However, the weak degree of cross-section indicates that the poor conductivity of $\mathrm{P}_{2} \mathrm{Cu}$. The same conclusion is obtained from the calculation of total density of states. From Fig.3(b), the total density of states (TDOS) of $\mathrm{PCu}_{3}$ is about 7 electrons/eV at Fermi level, which shows conductor property and relatively good conductivity, while that of $\mathrm{P}_{2} \mathrm{Cu}$ is near 1 electrons/eV from Fig.3(d), which shows poor conductivity. $\mathrm{PCu}_{3}$ is the best choice when used as anode materials for lithium ion battery.

\section{Conclusion}

In this paper, based on the first principle method, the CASTEP module is used to study the mechanism of lithium intercalation and deintercalation of $\mathrm{P}-\mathrm{Cu}$ alloy as anode material of lithium-ion battery. The results are as follows:

(1) The volume expansion coefficient of $\mathrm{Li}-\mathrm{P}-\mathrm{Cu}$ is small, 59.4650\% for $\mathrm{Li}_{2} \mathrm{PCu}_{3}$ and $61.4071 \%$ for $\mathrm{Li}_{2} \mathrm{P}_{2} \mathrm{Cu}$, indicating that the introduction of $\mathrm{Cu}$ can effectively inhibit the volume expansion of phosphorus.
(2) $\mathrm{PCu}_{3}$ shows the characteristics of conductor with good conductivity, while $\mathrm{P}_{2} \mathrm{Cu}$ shows poor conductivity.

(3) $\mathrm{PCu}_{3}$ is superior to $\mathrm{P}_{2} \mathrm{Cu}$ in terms of volume expansion coefficient and lithium intercalation formation energy and conductivity.

\section{Acknowledgments}

This work was financially supported by Guangdong Natural Science Foundation (2017A030313296), the Scientific and Technological Plan of Guangdong Province (2016A050503040, 2016B010114002).

\section{References}

1. Z.W. Huang, W.P. Xiao, J.Y. Li, L.Z. Zhao, IOP Conference Series: Earth and Environmental Science, 474, 052026(2020)

2. Y. Wu, W. Wang, J. Ming, M. Li, Y. Wu, Adv. Funct. Mater.,29,1805978(2019)

3. Z.W. Huang, W.P. Xiao, B.Q. Tang, S.J. Hu, Q. Ru, Iop Conference, 182, 012008(2017)

4. G. Shao, D.A.H. Hanaor, J. Wang, D. Kober, A. Gurlo, ACS Applied Materials \& Interfaces, 12, 46045 (2020)

5. W. Kong, Z. Wen, Z. Zhou, G. Wang, W. Sun, Journal of Materials Chemistry A, 7, 27048(2019)

6. H. Jin, H. Lu, W. Wu, S. Chen, J. Lu, Nano Energy, 70, 104569 (2020)

7. G.H. Lee, M.R. Jo, K. Zhang, Y.M. Kang, Journal of Materials Chemistry A, 5, 3683(2017)

8. J. Liu, A. Wu, R. Tian, R.A.P. Camacho, M. Yao Materials Today Energy, 18, 100545 (2020)

9. Y.S. Mun, Y. Yoon, J. Hur, M.S. Park, J. Bae, J.H. Kim, Journal of Power Sources, 362,115(2017)

10.J. Hu, P. Wang, P. Liu, G. Cao, G. Shao, Electrochimica Acta, 220, 258(2016) 